Print ISSN: 2234-3040 / Online ISSN 2234-3059

doi:10.13106/eajbm.2017.vol7.no4.11

[Review]

\title{
The Effectiveness on the Perception of Service Quality in MRO Transactions*
}

\author{
Kyoung-Jae $\mathrm{Im}^{* *}$, Ha-Ryong Kim**, Hoe-Chang Yang**** \\ Received: January 12, 2017. Revised: May 18, 2017. Accepted: July 15, 2017
}

\section{Abstract}

\begin{abstract}
Purpose - This study aims to provide a clue on which factors current managers and many more potential entrepreneurial applicants were required to concentrate on presenting effective research methods in the effects of purchasing companies' perception of service quality about suppliers of MRO industrial goods on the quality of relationships.

Research design, data, and methodology - To accomplish the purpose of this study, we plan to conduct a research model with factors of MRO service quality as the leading variables and conduct a causal analysis using regression analysis on their influence relations.

Results - In order to achieve the above purpose, it is necessary to select service quality factors suitable for the characteristics of MRO industrial goods supplier companies. And it is necessary to develop a plan for improving the relationship quality with buyer companies by understanding the sales orientation of MRO industrial goods supplier companies. Also, they develop a combined strategy capable of facilitating relationship quality by clarifying the role of rapport.

Conclusions - It is expected that these results will provide strategic clues which service quality factors should be improved from the perspective of supplier companies and will provide various information on educational training sales skills of the sales staff.
\end{abstract}

Keywords: MRO Transactions, Service Quality, Management Orientation, Rapport, Relationship Quality.

JEL Classifications: E20, E23, M10, M20, M31.

\section{Introduction}

Experts' expectations of business-to-business (B2B) companies bear quite extreme aspect. According to some media reports, it is more difficult for business-to-business (B2B) companies to generate revenue than business-toconsumer (B2C) companies. For instance, Economy21 expects that e-commerce based B2B companies are less likely to generate revenue in the next five years and only

* This paper has been represented KODISA 2016 Winter International Conference and awarded the Award of Excellence. Reviewed by new discussion of two panelists and revised faithfully reflected by three anonymous reviews.

** First Author, PhD Candidate, Graduate school of KnowledgeBased Technology \& Energy, Korea Polytechnic University, Korea. E-mail: withusim@naver.com

*** Co-Author, PhD Candidate, Dept. of Business Administration, Anyang University, Korea.

**** Corresponding Author, Assistant Professor, Dept. of Distribution Management, Jangan University, Korea.

Tel: +82-31-299-3133, E-mail: pricezzang@naver.com
$50 \%$ of them will have a surplus but $69 \%$ of B2C companies will make profits (Han, 2016). On the other hand, LG Electronics created a new B2B Division in 2014 and developed aggressive business based on the idea that B2B sectors can generate revenue more stable and secure higher profitability than $\mathrm{B} 2 \mathrm{C}$ transactions only if they have technical competence. As a result, LG Electronics takes a positive approach to $\mathrm{B} 2 \mathrm{~B}$ by presenting sales target for B2B in 2015 to approximately 4 trillion Korean won.

$\mathrm{B} 2 \mathrm{~B}$ industry is defined by industrial goods and intermediate goods markets distinguished from B2C as general consumer goods industry (Ahn \& Park, 2016; Jeon et al., 2009; Kim et al., 2014; Yim, 2017). Although B2B and $\mathrm{B} 2 \mathrm{C}$ are often included in many companies included in many companies to some extent, the classification of B2B and B2C varies according to purchase subjects and marketing aspects. In other words, it can be classified into B2C when the purchase subjects are consumers and B2B when they are organized purchasers, respectively. In addition, B2B is different from B2C in the following points: B2B deals with a small number of customers, customers' 
purchase motivation and purchase decision-making are more complex, and more than one person often affect purchase decision. Furthermore, it points out that there are differences between them in that B2B markets are induced by final consumer demand required in $\mathrm{B} 2 \mathrm{C}$ markets customers generally showing wide purchase frequency and they form differentiated uneven markets (Lilien, 1987).

The importance of service has expanded not only to industrial goods markets but also to B2B markets because service quality affects $B 2 B$ business more than industrial goods markets. Moreover, service quality serves as an important factor in purchase decision-making among decision-making related to transactions in B2B markets. On the other hand, Korean small and medium-sized enterprises required to compete in Korean B2B industrial goods market are put in fiercer competition by purchasers' various needs such as globalization of markets and technological changes.

This study focuses on how buying companies perceive the service quality of supplier companies in B2B industrial transactions because the services in $B 2 B$ markets have been more complex and various forms than those of consumer goods markets (Han \& Lee, 2012; Yang et al., 2013). In particular, among industrial goods this study focuses on, MRO is abbreviated from the initial letters such as Maintenance, Repair, and Operation and it is a term referring to consumable materials and office business operation for companies. In general, it means office supplies, cleaning supplies, tools, and machine parts. Recently, however, its concept has been extended to small facilities and services because there is a very high possibility of starting business easily in the industrial market related to MRO by the nature of products. Therefore, this study aimed to provide a clue on which factors current managers and many more potential entrepreneurial applicants were required to concentrate by presenting effective research methods in the effects of purchasing companies' perception of service quality about suppliers of MRO industrial goods on the quality of relationships.

\section{Theoretical Background}

A number of scholars have studied service quality, and it is a fact that there are various opinions and controversies in its definition. SERVQUAL is the most frequently used model proposed by Parasuraman et al. (1985, 1989). SERVQUAL measures service quality in five factors such as tangibles, reliability responsiveness assurance and empathy. However, because a variety of models related to service quality such as SERVQUAL and hierarchical model were mainly approached in the context of $\mathrm{B} 2 \mathrm{C}$, there are many limitations to applying this to B2B (Carman, 1990; Cronin \& Taylor, 1992; Grönroos, 1984; Lapierre \& Filiatrault, 1996). Therefore, Metcalf et al. (1992) and Woo and Ennew (2005) will provide clues on which factors small start-up companies should focus more by dividing B2B service quality into sub-categories such as exchange of products and services, information exchange, social exchange, cooperation, and adaptation.

Relationship quality can be defined as the level of correlation between service providers and buyers (Park, 2012). Levitt (1981) reported that a buyer-seller relationship is the beginning of a new relationship without ending up with buying or selling and proposed interdependence and continuous relationship as a means of sales management. Crosby et al. (1990) described the level of correlation as relationship quality and mentioned that customer evaluations of the relationship orientation of service providers consisted of reliability and satisfaction. Therefore, the quality of the relationship MRO industrial goods suppliers and buyers can be measured by various factors, and positive relationship quality can be an important factor capable of maintaining long-term transactional relationships.

This study focuses on sales orientation of supplier companies together with rapport as a factor required for MRO industrial goods supplying companies to improve the relation quality. Rapport means a relationship for consonance and harmony, or contact and communication, a psychological term referring mainly to mutual trust between two people, and a relationship 'to related to each other', 'capable of telling anything frankly', and to fully understand what the other person said' (Park, 2012). Tickle-Degnen and Rosenthal (1990) defined rapport as a mutual feeling formed when establishing a good relationship and getting along smoothly with others. Therefore, the level of rapport formation between supplier and buyer companies is considered as an important factor capable not only of maintaining long-term transaction relationships but also of improving the relationship quality.

In addition, it is a fact that e-commerce is used in combination with personal visit transactions by sales staff in B2B sales. Although standardized factors such as price and quality can be an important factor in purchase decision based on Internet in e-commerce, the tendency of sales staff can be a very important factor in personal visit transactions by sales staff. Therefore, when dividing the sales orientation of sales staff into customer market and solution orientation to analyze it, it was expected to provide clues to ensure competitiveness of MRO industrial goods supplier companies.

\section{Procedure and Propositions}

The service quality provided by MRO industrial goods suppliers will enhance the relation quality. Thus, it will provide various information on service provision of suppliers by confirming the role of sales orientation and rapport in their relationships. It is possible to conduct studies to improve relationship quality by the following procedures: 


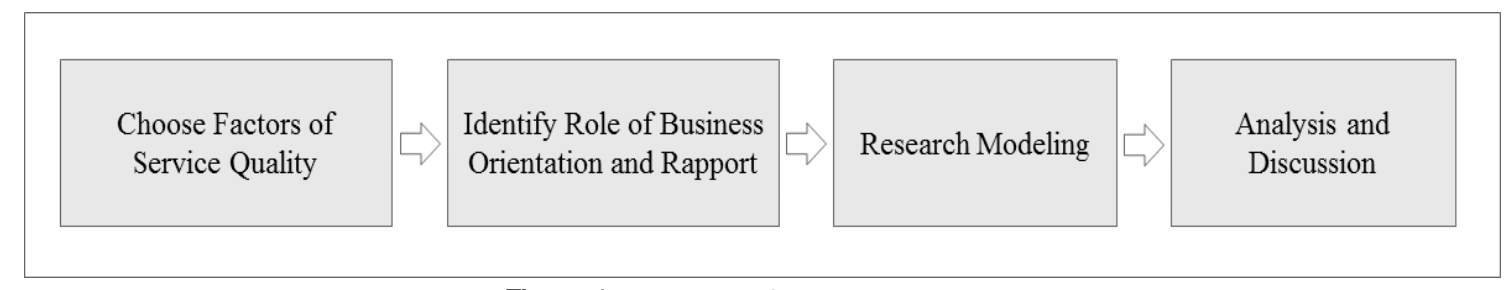

<Figure 1> Proposal of Research Procedure

<Proposition 1> It is necessary to select service quality factors suitable for the characteristics of MRO industrial goods supplier companies so that these factors can affect the purchase decision making of buyer companies.

In general, a marketing perspective is to approach the definition of user-centered quality among the definitions related to quality proposed by Garvin(1984). In other words, service quality is determined by users' perceptions and evaluations, and satisfaction and evaluation of service quality varies according to users' needs and expectations (Zeithaml, 1988). Therefore, because it is difficult to evaluate service quality objectively, the process of deriving service quality factors perceived from the customer perspective is very important. Services are not seen not only in consumer goods markets but also in B2B markets. Thus, it is hard to analyze the subjectivity of possible evaluations (Parasuraman et al., 1985; Smith, 1998), and there are various opinions about constructs(Carhuana et al., 2000).

The perceived service quality has been developed by the Nordic model by Grönroos (1984), SERVQUAL model proposed by Parasuraman et al. $(1985,1988)$, the threecomponent model by Rust and Oliver (1994) based on the two-dimensional model by Grönroos, and the multi-level model by Dabholker et al.(1996). However, because these models have been studied mostly in the context of consumer services, they may be somewhat different from B2B services. Therefore, industrial services should include services provided not only for individuals to make purchase decisions but also organizations.

<Proposition 2> It is necessary to develop a plan for improving the relationship quality with buyer companies by understanding the sales orientation of MRO industrial goods supplier companies.

Sales orientation of companies is the consideration from the customer perspective in the long term, and it is very important to help companies develop themselves by increasing customers' profits. Therefore, to divide the sales orientation of companies into customer, market, and solution orientation can be applied as a company concept capable of achieving the organizational goal through the establishment of trust with customers.
First, customer orientation is sales activities to increase customer satisfaction and reduce customer dissatisfaction in the long term, and the purpose of sales is to satisfy customer needs (Park, 2012). Thus, customer orientation can be defined as a marketing activity that sales staff make efforts to help customers make satisfactory purchase decisions (Saxe \& Weitz, 1982). Market orientation means efforts of companies required to cope better with market needs than other competitors to achieve competitive advantages continuously and to predict changes in market needs (Kim, 2013). Felton (1959) defined the market orientation as a company attitude to integrate all the marketing functions for cooperation by converging other functions to achieve the company goal to maximize the long-term profits. From this perspective, it can be considered that sales staff's efforts to integrate marketing functions in order to achieve the long-term goal of supplier companies are very important. It is true that solution orientation is related in part to the customer orientation. However, it can be summarized that the solution orientation means creative problem-solving and customers' desired value change (Jung, 2005). According to Jung (2005), it can be said that the solution orientation of sales staff is the customer orientation that is to say pro-active approach including even desired value changes beyond the level of satisfying customers' needs. Therefore, the sales orientation of companies, in particular, customer, market, and solution orientation, should be analyzed as a multidimensional concept, and it is possible to make good use of sales orientation strategies appropriately for the characteristics in each MRO product group by analyzing the effects on relationship quality.

<Proposition 3> It is necessary to develop a combined strategy capable of facilitating relationship quality by clarifying the role of rapport between the sales orientation of MRO industrial goods supplier companies and relationship quality.

Rapport in marketing, especially in the service sector, means that customers perceive pleasant relationship or bond with service providers. According to Macintosh (2009), familiarity had a positive effect on trust via rapport, and Ashforth and Humphrey (1993) reported that sincerity or consideration between customers and service providers was the core cause related to rapport formation. Thus, it is 
expected that the understanding of rapport will help MRO industrial goods supplier companies to not only facilitate pleasant relationships by interactions and to improve psychological trust but also to improve the quality of interactions ( $\mathrm{Ji}$ et al., 2010). If rapport plays an important role in increasing relationship quality, it is considered important for supplier companies to develop empathy capable of understanding the visions and goals of buyer companies and feelings, thoughts, and experiences of purchase decision makers.

Based on these propositions, this study can propose the summarized study model as follows and more various strategic clues will be found by subdividing service quality factors in a follow-up study.

\section{Expected Results}

The results obtained by the study procedures proposed in this study will indicate the direction to improve the service quality for MRO industrial goods suppliers by confirming which service factors buying companies expect more and perceive the lack. Moreover, they will provide a specific plan for enhancing the relationship quality by analyzing the effects of the sales orientation by sub-factor for MRO industrial goods suppliers. Furthermore, it will contribute to developing a marketing strategy of supplier companies by confirming the role of rapport between the sales orientation and relationship quality by phase with the role of the sales orientation between service quality and rapport. These results are expected to provide strategic clues which service quality factors should be improved from the perspective of supplier companies and provide various information on educational training sales skills of sales staff.

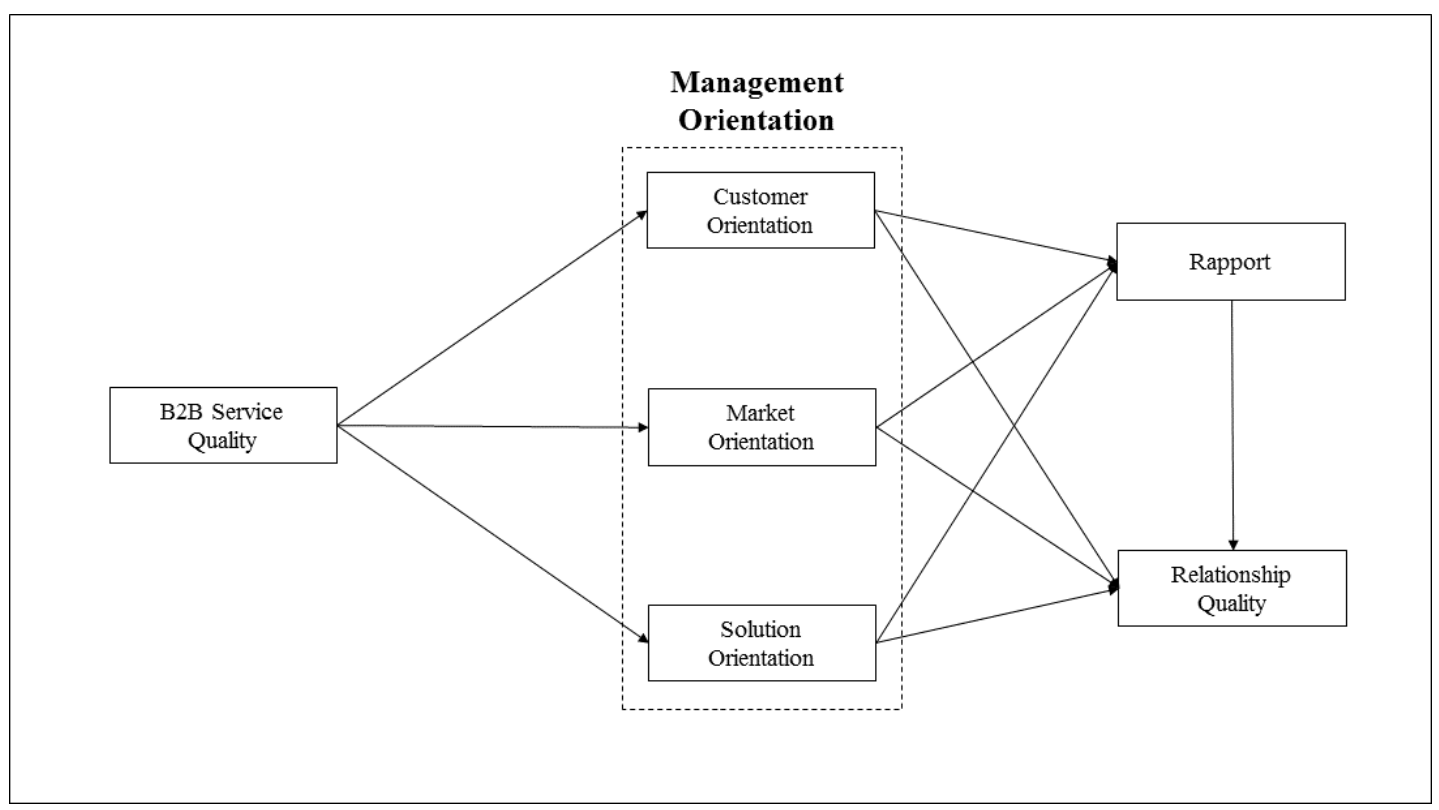

<Figure 2> Proposal of Research Model

\section{References}

Bloom, G., Segall, M., \& Thube, C. (1986). Expenditure and Financing of the Health Sector of Kenya Report. World Bank: Department of Population, Health and Nutrition.

Ensor, T. (1994). Public hospitals in developing countries: Resource use, cost, financing, by Howard Barnum and Josph Kutzin, John Hopkins university press, Baltimore and London, 1993. No. Of pages: 335.
ISBN0-8018-4532-7. Health Economics, 3(3), 207208.

Fakhrzade, H., Rasoulpour, E., \& Akhlaghi, M. (1999). Economic cost of coronary artery diseases in the oil industry of IRAN. South medicine, 3(1), 49-52.

Greene, B., Kralewski, J., Gans, D., \& Klinkel, D. (2002). A comparison of the performance of hospital- and physician-owned medical group practices. Journal of 
Ambulatory Care Management, 25(4), 26-36.

Jalali, A., \& Hoseini, M. (2001). Study of inpatients days in referral teaching hospitals and a general hospital. Health Economics Congress press, 1(3), 34-42.

Karimi, I. (2004). Health economics(2nd ed.), Tehran, Iran : Gap Publication.

McDermott, C., \& Stock, G. (2007). Hospital operations and length of stay performance. International Journal of Operations \& Production Management, 27(9), 1020-1042.

Saikhani, H. (2004). The role of quality management in determining the allocation of hospital resources.
Congress of resource management in hospitals, 1(4), 18-27.

Shepard, D. S., Hodgkin, D., Anthony, Y. E., Shephard, D. S., \& Staff, W. H. O. (2000). Analysis of hospital costs: A manual for managers. Geneva, Switzerland: World Health Organization.

Zandian, H., Olyaeemanesh, A., Takian, A., \& Hosseini, M. (2016). Contribution of targeted subsidies law to the equity in healthcare financing in Iran: Exploring the challenges of policy process. Electronic Physician, 8(2), 1892-1903. 